\title{
Innovative Construction of Online Teaching Models for "Double Teachers" Teachers in the Internet Era
}

\author{
Jie Cheng ${ }^{1}$, Birong Bie ${ }^{1}$ \\ ${ }^{1}$ Wuhan lnstitute Of Shipbuilding Technology,hubei Wuhan,430050, China
}

\begin{abstract}
Based on the teaching platform, the implementation of "dual-teacher" classrooms is different from the previous "large classes". Small classes scattered in different locations can share excellent teachers, which can not only ensure the quality of teaching, but also truly alleviate the shortage of teachers. This research first defines the concept of "dual-professional" teachers, and then clearly expounds the connotation and essential characteristics of "dual-professional" teachers, and analyzes the model construction of the current teacher team construction and "dual-professional" teacher team construction in China. Constructing an Internet-based "dual-professional" teacher innovation model, expounding the characteristics of dual-professional teaching and MOOC in detail, explaining the significance and advantages of blending dual-professional teaching and MOOC teaching, and studying related theories based on the foundation, then take this college as an example to summarize the mixed teaching practice of the curriculum fusion dual-teaching and MOOC teaching through case studies and make attribution analysis. The questionnaire survey method is used to investigate the learning data of students. The experimental results show that the students' three-dimensional goals can be achieved well under the mixed teaching; the comprehensive performance has been greatly improved, and the teaching effect of $1+1>2$ has been achieved; teachers and students are more satisfied with this blended teaching. At the same time, through the development of the mixed teaching practice of this course, teachers and students are familiar with MOOC teaching, discover and use high-quality MOOC resources on the Internet; arouse the interest of teachers and students in the construction of MOOC in this school; improve the information literacy of teachers and students.
\end{abstract}

\section{Introduction}

Implement + "dual teacher" teaching method, through teacher demonstration and guidance, promote the professional development of young teachers, improve the teaching level of young teachers, and create an excellent team of teachers [1-2], young teachers need a process of training and use at the same time, excellent teachers are needed to "deliver, help, and lead"[3]. Due to the lack of teachers in higher vocational colleges, teachers of all ages and young are busy teaching courses. It is difficult for old teachers to spend all their time training young teachers, while young teachers old teachers do not have all the time to teach [4-5], only the "double teacher" teaching method of "class teacher's class" can be adopted. "Lectures" can really make young teachers realize "teaching in middle school, teaching and learning". Teachers of all ages can kill two birds with one stone, and they also pay attention to work and study [6-7].

As an important online teaching resource, the online teaching platform has always been a hot research topic in the education field [8]. Riyono B uses the content analysis method. The article analyzes the network teaching platform research papers published on CNKI from 2003 to 2007 in three aspects: topic selection, research object, research object, and research object. The method and type research discusses the network The status quo and existing problems of teaching platform research, and suggestions for future research [9]. Vyazovskaya V V uses Twitter as an online teaching resource library. The SGR Twitter profile has been created. In 3 months, 23 SGR presentations were provided on Twitter. 93 students were invited to complete a questionnaire to evaluate the use of the knowledge base. 84 people $(90 \%)$ answered, of which $25(80.6 \%)$ thought it was "useful" to provide SGR online via twitter. The novel use of social media is a useful auxiliary educational tool when accessing the online repository of SGR presentations [10].

The development of "dual-professional" teachers or teaching ability is not a new research field, but it is a novel topic to put the research point of teaching ability under the background of "dual-professional" teachers. Innovation point 1: This article attempts to construct a structural model of the elements of teaching ability of dual-qualified teachers from three aspects. That is, the ability structure elements of general vocational education needs, the ability structure elements that highlight the quality of double teachers, and the ability demand elements under the new situation in my country. Innovation 2: On the basis of indepth analysis of related sub-concepts and connotations, it explores the various opportunities and challenges faced by 
"double-qualified" teachers in the development of teaching ability under the new situation, and provides practical references for future development strategies.

\section{Innovative Construction of Online Teaching Models for "Double Teachers" Teachers in the Internet Era}

\subsection{Innovation of the "Dual Teacher" Teacher Model Based on the Internet Environment}

School-based training teacher system: This system is mainly in charge of the school-based training leading group, with the assistance of the Office of Educational Affairs for the construction. This system mainly summarizes and summarizes the specific situations of the trained teachers selected by the school, and puts them in the resource bank as training talents.

Consultation and interactive system: This system is composed of several small units of expert blogs, including Weibo, online communication, and contention of a hundred schools of thought. The school-based training leading group is fully responsible for the construction. All "dual teacher" teachers and relevant teaching and research staff of the Education Bureau's teaching and research section participate in the construction. It is mainly through these small platforms to promptly solve the various problems that appear in the daily teaching and education process for each "dual teacher" teacher, innovate various teaching concepts and thinking under the guidance of experts, and enhance personal integration literacy.

\subsection{Construction of a Model for the Construction of "Dual-Qualified" Teachers in Local Undergraduate Universities}

Using Amos21.0 for data fitting and testing the structural equation model, the relationship between the factors in the model was verified. The following goodness-of-fit evaluation indexes are obtained. Among them, the $\mathrm{x} 2$ test data is 2552.542 , GFI is .728, GFI is .532, NFI is .532, if it is .532.

The standard path coefficient $\beta=0.01$, the critical ratio C.R. $=6.028$, and the significance level $\mathrm{P}=0.000<0.001$. Hypothesis $\mathrm{H} 1$ is confirmed. The standard path coefficient $\beta=0.9$, the critical ratio C.R. $=69.380$, and the significance level $\mathrm{P}=0.000<0.001$. The $\mathrm{H} 3$ hypothesis was confirmed.

The core-based perceptron algorithm needs to store and update a function $\mathrm{ft}$ during the iteration process:

$$
\mathrm{f}_{\mathrm{t}}(\cdot)=\sum_{\mathrm{i} \in \varepsilon_{\mathrm{t}}} \mathrm{y}_{\mathrm{i}} \mathrm{K}\left(\mathrm{x}_{\mathrm{i}}, \cdot\right)
$$

The stochastic gradient descent method to solve the kernel-based online learning algorithm is:

$$
\mathrm{L}\left(\mathrm{f}, \mathrm{x}_{\mathrm{t}}, \mathrm{y}_{\mathrm{t}}\right)=\min e\left(\mathrm{f}\left(\mathrm{x}_{\mathrm{t}}\right), \mathrm{y}_{\mathrm{t}}\right)+\frac{\lambda}{2}\|\mathrm{f}\|
$$

Here $\eta$ is the learning rate.

Let $\mathrm{fl}=0$, then $\mathrm{ft}$ can be expressed as:

$$
f_{t}(x)=\sum_{i=1}^{t-1} a_{i} K\left(x_{i}, x\right)
$$

It can be seen from the expression of $\mathrm{ft}(\mathrm{x})$ that when the number of samples tends to infinity, the number of kernel terms will also tend to infinity. The update rule of the coefficient $\alpha$ solves this problem well.

\section{Experiments on the innovative construction of the online teaching model of "dual teacher" teachers in the Internet era}

Training object: Students of the college

Training content: The public training content of the teaching and research group is a topic album. The learning content of the self-study part of the teaching research group is based on the content selected by the individual.

Training method: The public training part of the teaching and research group adopts the learning method of "trained teacher-led, training teachers, and resource library support". The learning content of the self-study part of the teaching and research group is carried out according to the learning method selected by the individual.

After the end of this course, the students' learning data and teaching effects were analyzed through questionnaire surveys, and students' learning experience and feelings about this mixed teaching were interviewed. At the same time, they interviewed the teachers of the mixed teaching and MOOC. Views and suggestions on teaching practice.

The questionnaire is designed and made on the questionnaire star. The questionnaire is designed around three parts: classroom teaching feedback in mixed teaching, MOOC teaching experience, and the harvest of mixed teaching. The link of the questionnaire was sent to the class QQ group to allow students to complete the questionnaire, and 120 questionnaires were collected.

\section{Experimental Research on the Innovative Construction of Online Teaching Models for "Double Teachers" Teachers in the Internet Age}

\subsection{Online Teaching Results of "Dual-Qualified" Teachers}

On the basis of the Internet, the "dual teacher" teaching is implemented. A lecturer and many teachers attend classes together. In order to ensure the connection of the teaching process, we need a lecturer and enough teachers to prepare lessons together. Each lesson is the crystallization of the wisdom of many teachers, and the application process of each type is also very standardized. With the recording and broadcasting module of the platform, we can record highquality educational content, teaching design, teaching organization and the formation of digital learning resources. In the school's excellent educational resource server, students can study independently after class without being restricted by time and space.

In terms of system construction, hard investment and soft investment, salary distribution reform, etc., corresponding systems and supporting policies have been introduced. In terms of system construction, schools should introduce the main lecturers and trainers of the 
"dual-teacher" teaching method. In terms of software and material investment, in view of the need to strengthen the transformation process of school information technology, use information technology to promote the improvement of teaching quality and strengthen Investment in on-site learning platform software and teaching materials, strengthening the construction of the digital learning resource library, the distribution of class wages and the reduction of teacher wages.

The learning effect evaluation method uses a variety of evaluation methods. Combining students' video learning, online homework, daily posting, online testing, and traditional classroom results (attendance and classroom performance) and experimental results on the MOOC, a variety of evaluation methods coexisting assessment methods are adopted. After the course is over, evaluate the students' teaching practice for one semester.

According to the evaluation criteria, the total scores of traditional classrooms include usual scores and experimental scores. The final scores of students are calculated using Excel as shown in Table 1. Set 90 points or more as excellent and 80 points to 89 points as good. A score of 70-79 is considered medium, a score of 60-69 is considered a pass, and a score below 60 is considered a fail. The analysis of student achievement data is shown in Figure 1.

Table 1. Result analysis table

\begin{tabular}{|c|c|c|}
\hline Grades & $\begin{array}{c}\text { Number of } \\
\text { people }\end{array}$ & $\begin{array}{c}\text { Proportion of total } \\
\text { investment (\%) }\end{array}$ \\
\hline Above 90 (excellent) & 20 & 16.66 \\
\hline $80-89$ (good) & 49 & 40.83 \\
\hline $70-79$ (medium) & 21 & 17.5 \\
\hline $60-69$ (pass) & 20 & 16.66 \\
\hline Below 60 (fail) & 10 & 8.33 \\
\hline
\end{tabular}

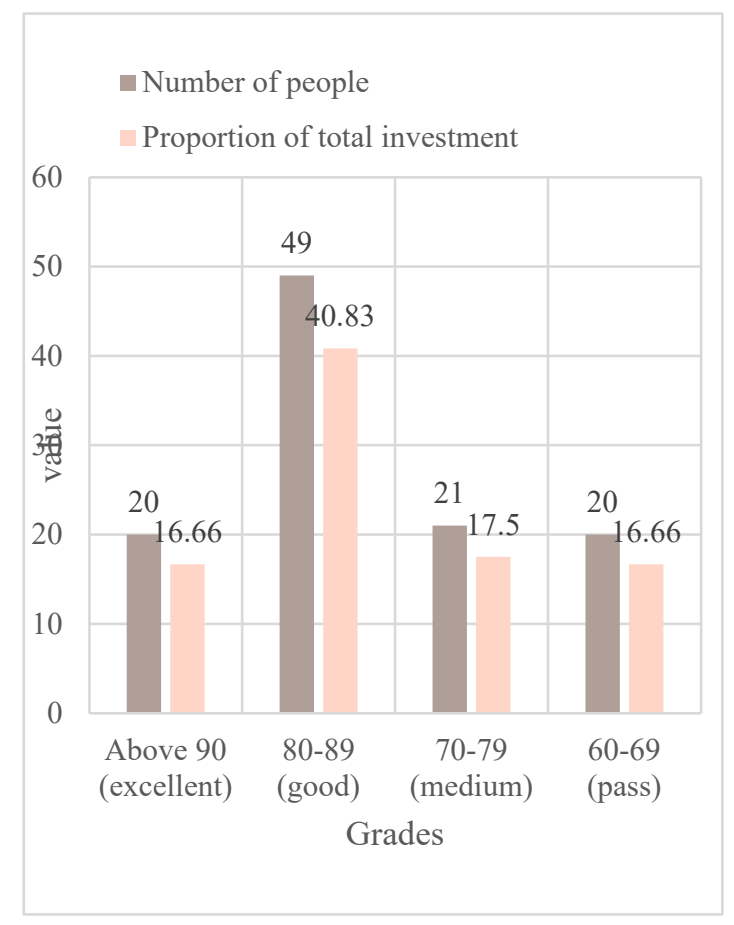

Figure 1. Performance analysis

According to the survey results, the role of teachers in "dual-teacher" teaching is mainly divided into two roles: knowledge transmitter and guide. A few students think that they are managers or other roles. It shows that the classroom under this teaching is a dual-primary teaching form led by teachers and students as the main body. In teaching, teachers have a variety of teaching methods. According to the proportion of students' choices, they mainly include narration method, multimedia teaching method, intuitive demonstration method, group study, discussion method, task-driven method, etc.

\subsection{Analysis of Satisfaction with Online Teaching of "Dual-Qualified" Teachers}

Investigate how the teaching practice under the online teaching mode of "dual teacher type" teachers helps students learn. The specific investigation of the students' grasp of basic computer knowledge, the improvement of autonomous learning ability, the improvement of analysis problem-solving ability and the improvement of teamwork ability under mixed teaching are all very helpful. The details are shown in Table 2:

Table 2. The help of "double qualified" teachers in online teaching

\begin{tabular}{|c|c|c|c|}
\hline & $\begin{array}{c}\text { Helpful } \\
(\%)\end{array}$ & $\begin{array}{c}\text { Average } \\
(\%)\end{array}$ & $\begin{array}{c}\text { Didn't } \\
\text { help }(\%)\end{array}$ \\
\hline $\begin{array}{c}\text { Grasp of basic } \\
\text { knowledge }\end{array}$ & 77 & 20 & 3 \\
\hline $\begin{array}{c}\text { Autonomous } \\
\text { Learning Ability }\end{array}$ & 70 & 18 & 12 \\
\hline $\begin{array}{c}\text { Problem solving } \\
\text { ability }\end{array}$ & 79 & 15 & 6 \\
\hline $\begin{array}{c}\text { Teamwork } \\
\text { ability }\end{array}$ & 65 & 17 & 18 \\
\hline
\end{tabular}




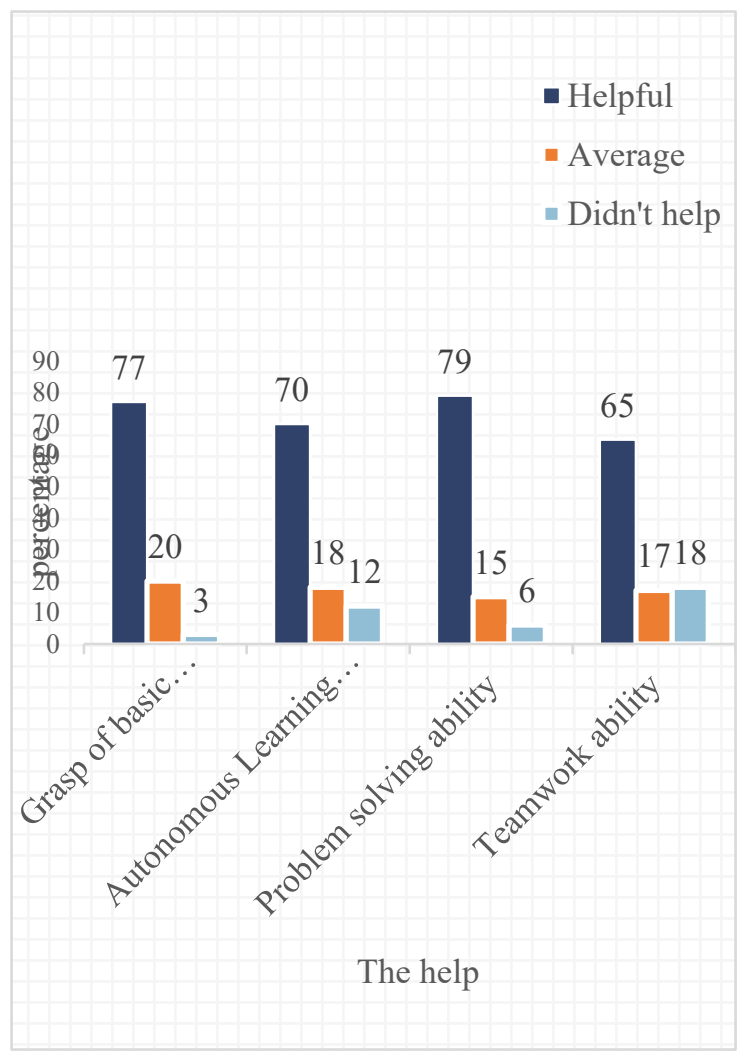

Figure 2. The help of "double qualified" teachers in online teaching

Satisfaction survey feedback on the evaluation method: In the practice of mixed teaching, the evaluation of students is designed as a multiple evaluation method that combines process evaluation and summative evaluation. Through the survey, it is found that this kind of evaluation method has been favored by the majority of students. $70 \%$ of the students think that this kind of evaluation method is reasonable, $30 \%$ of the students think it is fair, and zero think it is unreasonable. By investigating the learning effects of students in the online online teaching of "dualteacher" teachers, the effectiveness of the hybrid teaching reform is evaluated. According to the following data, $40 \%$ of students think that this teaching method is effective, $20 \%$ are higher, $21 \%$ are generally $21 \%$, and only $15 \%$ are lower and 4\% are lower. Investigate students' interest in courses after conducting online teaching practice with "dual teacher" teachers. $35 \%$ of students are very interested, $45 \%$ of students are interested, and $19 \%$ of students are generally interested in courses, $1 \%$ of students said they were not interested. From the survey results, after the "dual teacher" teacher online teaching practice, students' interest in the course has increased significantly. After trying the online teaching practice of "dual-teacher" teachers, investigate the students' satisfaction with this kind of teaching. $38 \%$ of the students said they liked it very much, $38 \%$ of the students liked it, $4 \%$ of the students who disliked the online teaching of the "dual teacher" teacher accounted for $4 \%$, the students who disliked it accounted for $10 \%$, and the remaining $10 \%$ of the students said that the attitude of "dual teacher" teachers on online teaching feels average. On the whole, students are more satisfied with the online teaching of the "dual teacher" teacher.
The data from the questionnaire shows that this hybrid teaching mode that combines dual-teaching and MOOC teaching helps students better master the threedimensional goals, greatly improves the learning effect of students, and is loved by the majority of students. It shows that the practice under the "dual teacher" teacher online teaching mode is very meaningful.

\section{Conclusions}

Nowadays, the development of dual-qualified teaching is in the ascendant. The research on dual-qualified teaching has undoubtedly strengthened the system of dual-qualified teaching and dual-qualified research once again, laying a solid foundation for the development of educational science. This research is based on the teaching innovation model of dual-qualified teachers. The focus of the research is to explore the development strategy of teaching ability. The research ideas of this article can be summarized as follows: This article uses a variety of research methods. This article uses the literature writing method to study the status quo of college teachers "dual-teaching". Secondly, it uses the method of network investigation to collect relevant literature. Through the analysis and combing of the theoretical system of teaching ability, it has laid a solid foundation for the entire research. Finally, it puts forward practical and feasible countermeasures in line with the national conditions and reliable development countermeasures.

Project: key project of Vocational and technical education branch of Chinese society of higher education "Research on the construction and guarantee mechanism of teaching innovation team in Higher Vocational Colleges from the perspective of collaboration", project number (gzyz2019006), principal: Cheng Jie.

\section{References}

1. Du G, Chen M, Liu C, et al. Online Robot Teaching With Natural Human-Robot Interaction[J]. IEEE Transactions on Industrial Electronics, 2018, PP(99):1-1.

2. Liu H, Liu Y, Feng J . The Realistic Dilemma and Breakthrough Ways of Improving the Quality of Online Teaching Resources of Physical Education in Colleges and Universities[J]. Advances in Physical Education, 2021, 11(1):1-11.

3. Noor S , Md F, Mazhar F F . Online Teaching Practices During the COVID-19 Pandemic[J]. Educational Process International Journal, 2020, 9(3):169-184.

4. Li Y, Zhang R, Yang Y . Practice of Distance Online Teaching of Automobile Theory[J]. Open Access Library Journal, 2021, 08(1):1-5.

5. Vijay R . Comparative evaluation of COVID-19 pandemic enforced online teaching versus traditional teaching from point of view of medical students[J]. 
International Journal of Basic \& Clinical Pharmacology, 2021, 10(1):36-43.

6. Taylor S C, Phillips R, Kee Y . Improving Critical Thinking Skills in Online Teaching[J]. Social Economy \& Policy Studies, 2020, 10(1):1-28.

7. Malik S . A study of parent's opinion on online teaching in Delhi-NCR schools[J]. Indian Journal of Science and Technology, 2020, 13(42):4351-4363.

8. Galikhanov M F , Khasanova G F . Faculty Training for Online Teaching: Roles, Competences, Contents[J]. Vysshee Obrazovanie $\mathrm{v}$ Rossii $=$ Higher Education in Russia, 2019, 28(2):51-62.

9. Riyono B , Rifkianti W . Android-Based Information System Of Online Teaching Services With GeoLocation Determination[J]. bit-Tech, 2018, 1(1):9-18.

10. Vyazovskaya V V, Danilevskaya T A, Trubchaninova $\mathrm{M}$ E. Online resources in teaching Russian as a foreign language: expectations vs reality[J]. Russian Language Studies, 2020, 18(1):69-84. 